\section{Assessment of the LiX salt-effect in anthracenyl lithiums $\dagger$}

\author{
Daniel Stern, Nils Finkelmeier and Dietmar Stalke* \\ Received 23rd July 2010, Accepted 27th November 2010 \\ DOI: $10.1039 / \mathrm{c0cc02772c}$
}

Based on lithium anthracenes RLi, the formation of mixed complexes from organolithiums and lithium salts $\mathrm{RLi} \cdot \mathrm{LiX}$ is illustrated. The $[\mathrm{RLi}(\mathrm{L})]_{2}$ dimers formed in presence of different donating solvents $\mathrm{L}$ as well as the corresponding mixed lithium bromide complexes $[\mathrm{RLi}(\mathrm{L}) \cdot \mathrm{LiX}]$ were isolated and structurally characterized.

Since their discovery by Schlenk and Holtz in 1917, ${ }^{1}$ organolithiums have emerged as the leading tool in organometallic chemistry. ${ }^{2}$ Aside from their strong nucleophilic characteristics, organolithiums are as easy to handle as they are synthesized, which broadens their spectrum of application from research laboratory work ${ }^{3}$ to large scale industrial processes. ${ }^{4}$ Closely followed by sterically demanding lithium amides, organolithiums are the reagent of choice in deprotonation and metallation reactions.

In the past decade the addition of lithium halide salts to organometallics rapidly gained importance in the cutting-edge development of avant-garde metallation reagents. Especially, turbo Grignards developed by Knochel et al. ${ }^{5}$ and alkalimetal-mediated metallations developed by Mulvey et al. ${ }^{6}$ have attracted great attention in this context. The addition of lithium chloride to the Grignard reagent not only results in a significant structural alteration, but also notably influences the reactivity and functional group tolerance.

Although this potent method of reactivity adjustment by LiX-salt addition has been applied to organolithiums, ${ }^{7}$ tailoring reactivity for lithium organic compounds has mostly been limited to the well known mechanisms of disaggregation by addition of donor bases. ${ }^{8}$ Especially, when the starting material contains several functional groups of marginally different reactivity, this reactivity grading is often too limited. Hence, poor yields or complicated work-up procedures often require the exploitation of different routes.

Although the formation of mixed LiX-complexes has been observed for organolithiums in the past, ${ }^{9}$ this phenomenon was mostly perceived as an obstacle. For example the loss in

Institut für Anorganische Chemie der Universität Göttingen,

Tammannstraße 4, 37077 Göttingen, Germany.

E-mail:dstalke@chemie.uni-goettingen.de; Fax: +49-551-39-3459;

Tel: + 49-551-39-3000

$\dagger$ Electronic supplementary information (ESI) available: Experimental, crystallographic and quantum chemical data, including the coordinates of all the species. CCDC 766244-766247. For ESI and crystallographic data in CIF or other electronic format see DOI: 10. $1039 / \mathrm{c} 0 \mathrm{cc} 02772 \mathrm{c}$ reactivity observed in reactions of $\mathrm{PhLi}$ and $n \mathrm{BuLi}$ were ascribed to the formation of mixed aggregates with lithium halides. $^{10}$

The occurrence of diminished reactivity was also reported by Power et al. ${ }^{8 c}$ They structurally characterized one of only two mixed RLi.LiX-complexes known so far. Their $\left(\left[\mathrm{Ph}_{3} \mathrm{Li}_{4} \mathrm{Br} \cdot\left(\mathrm{Et}_{2} \mathrm{O}\right)_{3}\right]\right)$ complex and the $\left(\left[\mathrm{Cy}_{2} \mathrm{Li}_{4} \mathrm{Br}_{2} \cdot\left(\mathrm{Et}_{2} \mathrm{O}\right)_{4}\right]\right)$ complex synthesized by Schmidtbaur et al. ${ }^{11}$ show similar tendencies regarding the $\mathrm{Li}-\mathrm{C}_{\alpha}$ bond lengths and increased stability towards air.

Although the occurrence of mixed LiX complexes in e.g. elementary Gilman type reactions seems long forgotten, it might turn out that they are on par with the turbo-Grignards $\mathrm{RMgX} \cdot \mathrm{LiCl}$ recently developed by Knochel et $a .^{5}$ and the turbo-Hauser Bases developed by Mulvey et al. ${ }^{12}$ While their enhanced reactivity clearly widens the application of these classical organometallic reagents the reduced reactivity of the $\mathrm{R}_{m} \mathrm{Li}_{m+n} \mathrm{X}_{n}$ species might be beneficial to the tolerance of various functional groups. In $\mathrm{C}-\mathrm{C}$-bond formation reactions of organolithiums with alkyl or aryl halides lithium halides are formed in equimolar amounts and it might be energetically and stereochemically advantageous if the $\mathrm{LiX}$ reaction product is already preorganized in the starting material. ${ }^{13}$

In this light we revisited the $\mathrm{R}_{m} \mathrm{Li}_{m+n} \mathrm{X}_{n}$ complexes to shed some light on their aggregation and possibly redirect the perception of mixed aggregates regarding their synthetic potential, rather than just discharging them as problematic side effects.

To acquire further information regarding the influence of lithium halide salts on the structure of halide-free versus

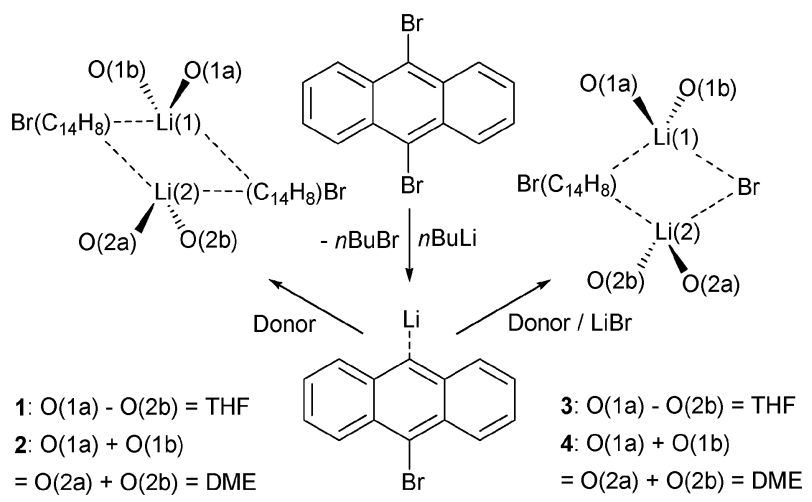

Scheme 1 Formation and disaggregation of lithiated anthracenes from bromo anthracenes in presence and absence of lithium bromide. 
mixed-halide organolithiums we synthesised and crystallized both species to compare their structures. We selected lithiumanthracenes which form dimeric aggregates with monoand bidentate donor bases due to their own sterical demand. As we have already shown in our previous work, monolithiated anthracenes can be obtained in a Gilman type reaction from brominated anthracenes ${ }^{14}$ and their reactivity can be adjusted by the consecutive exchange of donor bases. ${ }^{15}$ Employing $n \mathrm{BuLi}$, all bromo anthracenes investigated so far can easily be converted to the corresponding lithium derivatives in nearly quantitative yields (Scheme 1).

The lithium aryls obtained via this reaction always form $\left[\mathrm{R}\left(\mathrm{C}_{14} \mathrm{H}_{8}\right) \mathrm{Li} \cdot(\text { Donor })_{n}\right]_{2}$ with $n=1$ or 2 dimeric aggregates when coordinated to a monodentate or bidentate donor. After isolation of the dimer and separation from the $n \mathrm{BuBr}$ by washing the product with hexane, the pure ether complex $\left[\mathrm{R}\left(\mathrm{C}_{14} \mathrm{H}_{8}\right) \mathrm{Li} \cdot\left(\mathrm{Et}_{2} \mathrm{O}\right)\right]_{2}$ is obtained. When this complex is re-dissolved in diethyl ether, the addition of the donor bases THF (tetrahydrofurane) or DME (dimethoxy ethane) leads to the dimeric aggregates $\left[\mathrm{R}\left(\mathrm{C}_{14} \mathrm{H}_{8}\right) \mathrm{Li} \cdot(\text { thf })_{2}\right]_{2} \quad$ (1) $)$ and $\left[\mathrm{R}\left(\mathrm{C}_{14} \mathrm{H}_{8}\right) \mathrm{Li} \cdot(\mathrm{dme})\right]_{2}(\mathbf{2}) \ddagger$. If one equivalent of solvated lithium bromide is admixed to these solutions (prepared as a standard solution in THF), the mixed complexes $\left[\mathrm{R}\left(\mathrm{C}_{14} \mathrm{H}_{8}\right) \mathrm{Li} \cdot \mathrm{LiBr} \cdot(\mathrm{thf})_{4}\right]$ (3) $\ddagger$ and $\left[\mathrm{R}\left(\mathrm{C}_{14} \mathrm{H}_{8}\right) \mathrm{Li} \cdot \mathrm{LiBr} \cdot(\mathrm{dme})_{2}\right](\mathbf{4}) \ddagger$ are obtained. The crystal structures of compounds $\mathbf{1}$ to $\mathbf{4}$ are depicted in Fig. 1 and selected bond distances and angles are compiled in Table $1 . \ddagger$

The dimers $\mathbf{1}$ and $\mathbf{2}$ show structural features that are characteristic of lithium aryls. The anthracene carbanionic anellated rings of the dimers stay nearly planar and are bridged by a planar four-membered $(\mathrm{Li}-\mathrm{C})_{2}$ ring, which is oriented orthogonally to the anthracene mean plane. One lithium atom (Li1) is almost located in that plane in a $\sigma$-bonding position while the second is more shifted to a $\pi$-bonding situation. This results in a parallel shift of the anthracene carbanions and the formation of an asymmetric $(\mathrm{Li}-\mathrm{C})_{2}$ ring, that consists of a short $\mathrm{Li}-\mathrm{C}-\sigma$ bond (av. $2.26 \mathrm{pm}$ ) and a long $\mathrm{Li}-\mathrm{C}-\pi$ bond (av. $2.36 \mathrm{pm}$ ). This reflects the $\mathrm{sp}^{2}$-hybridisation of the lithiated carbon atom $\mathrm{C}_{\alpha}$. The averaged $\mathrm{Li}-\mathrm{C}_{\alpha}$ bond lengths (2.305(5) in $\mathbf{1}$ and 2.309(6) pm in 2) are almost identical. Replacement of an anthryl anion by a bromide anion results in a quite different structure. Although the $\mathrm{CLi}_{2} \mathrm{Br}$ four membered ring is still

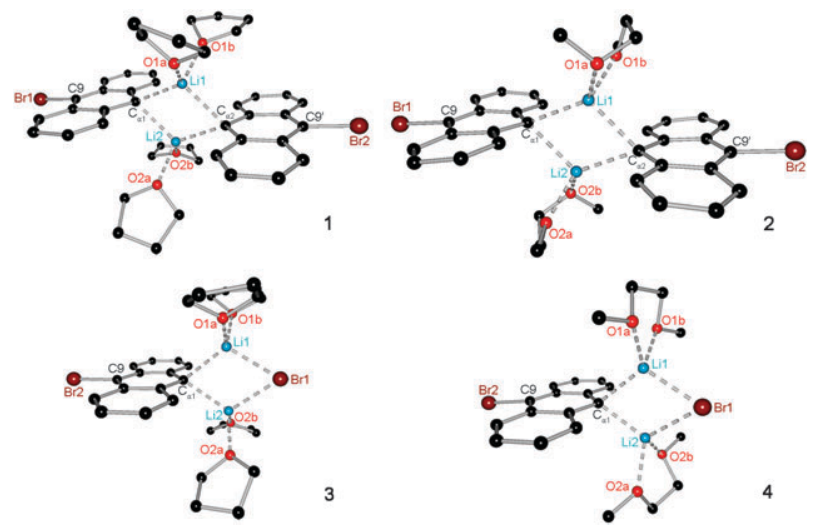

Fig. 1 Crystal structures of $\mathbf{1}$ to $\mathbf{4} \nmid$. Hydrogen atoms and disorder of DME in 4 are omitted for clarity. Selected bond lengths: av. $\mathrm{Li}-\mathrm{C}_{\alpha}=2.305(5)$ 1, 2.309(6) 2, 2.298(11) 3, 2.225(9) 4. arranged orthogonal to the mean plane of the carbanion, both lithium atoms are now equidistant from that plane indicating a slight rehybridisation of the $\mathrm{C}_{\alpha}$ atom towards $\mathrm{sp}^{3}$. However, this view is not substantiated by the inner $\mathrm{C}-\mathrm{C}_{\alpha}-\mathrm{C}$ angles. Despite the fact that an $\mathrm{sp}^{3}$ carbon atom is wider in radius, the averaged $\mathrm{Li}-\mathrm{C}_{\alpha}$ bond lengths decrease (2.298(11) in $\mathbf{3}$ and 2.225(9) pm in 4), indicative of stronger bonding and reduced reactivity. ${ }^{15}$ This is valid for all known examples so far. The mixed aggregates show greater stability towards temperature and atmospheric oxygen compared to the parent organolithiums. Crystalline $\mathbf{3}$ and $\mathbf{4}$ are stable for hours at room temperature and decompose fairly slowly under contact with atmospheric oxygen, while 1 and 2 decompose instantaneously above $-10{ }^{\circ} \mathrm{C}$ or in contact with air. In the presence of wet solvents or water, however, all compounds hydrolyze immediately.

Mixed aggregates, which have earlier been described as a quiescent state, ${ }^{16}$ can easily be reactivated by addition of multidentate donors. The reactivation at this stage does not take place via the established mechanisms of disaggregation, but by precipitation of the lithium salt from the equilibrium. The stability and the lattice energy of the formed LiX.donor complexes is the driving force of this activation process.

The assumed reduction in reactivity due to co-complexation of lithium halides is presumably responsible for many phenomena which could often not be explained in the past. A good example for such a case is given by the deprotonation of the ligand $\mathrm{PhP}\left(\mathrm{CH}_{2} \mathrm{Py}\right)_{2}$ (Scheme 2). When the ligand is synthesized according to the reaction pathway described by Lindner et al. ${ }^{17}{ }^{1}$ lithium chloride is formed during the reaction, which is co-complexed by the ligand and thus can not be removed. Hence, nobody would anticipate the salt in the phosphane product. It was never identified to be present. When this product is dissolved and reacted with $n-\mathrm{BuLi}$, the deprotonation of the bridging methylene groups is prevented. So a new synthesis of the same ligand was developed, which avoids the formation of lithium chloride. ${ }^{18}$

The lithium halide-free product obtained via this reaction pathway can readily be deprotonated in nearly quantitative

Table 1 Selected bond lengths and angles in $\mathbf{1}$ to $\mathbf{4} \ddagger$
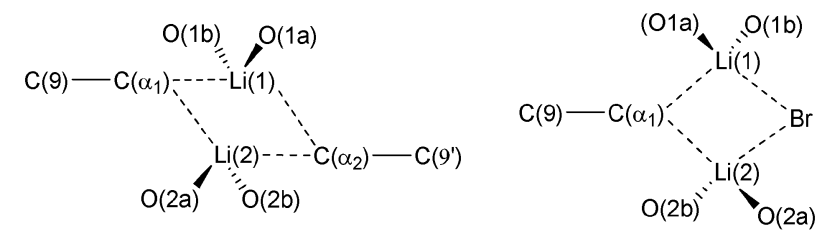

\begin{tabular}{lllll} 
& \multicolumn{1}{c}{$\mathbf{1}$} & $\mathbf{2}$ & $\mathbf{3}$ & \multicolumn{1}{c}{$\mathbf{4}$} \\
\hline & $\mathbf{1}$ & $\mathbf{2}$ & $\mathbf{3}$ & $\mathbf{4}$ \\
\hline $\mathrm{C}\left(\alpha_{1}\right)-\mathrm{Li}(1)$ & $2.250(5) / 2.271(5)^{a} \S$ & $2.256(6)$ & $2.287(11)$ & $2.219(8)$ \\
$\mathrm{C}\left(\alpha_{1}\right)-\operatorname{Li}(2)$ & $2.363(5) / 2.368(5)^{a} \S$ & $2.361(6)$ & $2.308(11)$ & $2.231(9)$ \\
$\mathrm{C}\left(\alpha_{2}\right) / \operatorname{Br}(1)-\operatorname{Li}(1)$ & $2.347(5) / 2.353(5)^{a} \S$ & $2.361(6)^{b}$ & $2.502(10)$ & $2.459(7)$ \\
$\mathrm{C}\left(\alpha_{2}\right) / \operatorname{Br}(1)-\operatorname{Li}(2)$ & $2.248(5) / 2.242(5)^{a} \S$ & $2.256(6)^{b}$ & $2.514(10)$ & $2.494(7)$ \\
av. $\operatorname{Li}-\mathrm{C} \alpha$ & $2.30525(50)$ & $2.3085(60)$ & $2.502(10)$ & $2.225(9)$ \\
av. $\operatorname{Li}-\operatorname{Br}(1)$ & & & $2.508(10)$ & $2.3265(70)$ \\
$\mathrm{Li}(1)-\mathrm{C}\left(\alpha_{1}\right)-\operatorname{Li}(2)$ & $67.2(2)$ & $65.2(2)$ & $73.3(4)$ & $78.8(3)$ \\
$\mathrm{Li}(1)-\operatorname{Br}(1)-\operatorname{Li}(2)$ & & & $66.26(30)$ & $66.16(20)$ \\
${ }^{a}$ \& Two crystallographically & independent & dimers. ${ }^{b}$ & Symmetry \\
identical values. & & & &
\end{tabular}




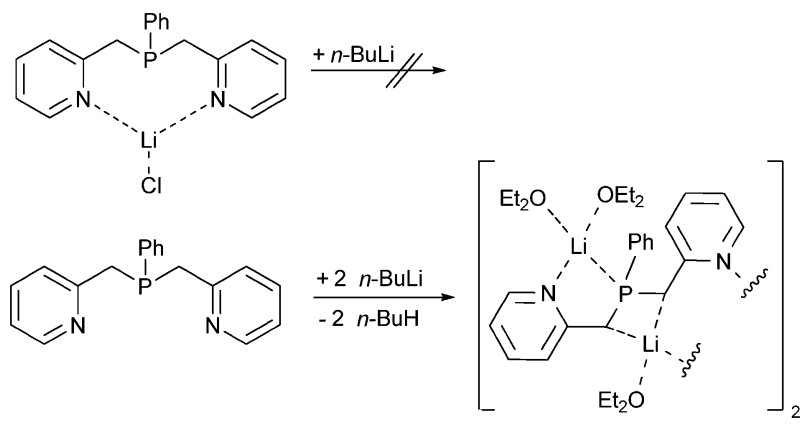

Scheme 2 Prevented and facilitated metallation of $\mathrm{PhP}\left(\mathrm{CH}_{2} \mathrm{Py}\right)_{2}{ }^{19}$

yield employing $n$-BuLi under the same conditions applied to the $\mathrm{LiCl}$ co-complexed phosphane. ${ }^{19}$

The prevented metallation can be attributed to the formation of mixed $\mathrm{LiCl}$-complexes from $n$-BuLi and lithium chloride. Analogous to the DME molecules described in this paper, the $\mathrm{PhP}\left(\mathrm{CH}_{2} \mathrm{Py}\right)_{2}$ ligand acts as a bidentate donor which coordinates the lithium atoms. Hence, the reactivity of this mixed aggregate is not sufficient for the deprotonation of the methylene groups.

This paper suggests that reactions in which lithium salts are generated follow far more complicated mechanisms and equilibria than commonly anticipated. Although the assumptions from the widely accepted concept of reactivity enhancement by disaggregation sometimes cause the same effects, only the exact knowledge of the processes taking place during the reaction can explain unexpected phenomena. Thus, in reactions in which lithium salts are formed as a by-product, at least two equivalents of a polydentate donor base are required to achieve complete disaggregation down to the monomer.

In conclusion, we have shown that the formation of mixed aggregates has a strong influence on the structure and reactivity of organolithiums. Addition of lithium halides features the opportunity to adjust the reactivity and selectivity of organolithiums beyond the approved mechanisms of disaggregation via the addition of multidentate donor bases. This substance class should especially find applications in reactions of compounds that hold a multitude of functional groups and therefore require a maximum of selectivity. Furthermore, the fine-tuning of the reactivity by shifting the equilibrium between the $\mathrm{R}_{m} \mathrm{Li}_{m+n} \mathrm{X}_{n}$ mixed halide complex and the parent $\mathrm{R}_{m} \mathrm{Li}_{m}$ organolithiums with multidentate donors might have considerable potential in synthetic chemistry. The impact of other lithium salts as well as kinetic studies, which will give more detailed information on the reactivity of mixed complexes, will be subject of further research.

\section{Notes and references}

$\ddagger$ Crystallographic details: Shock cooled crystals were selected and applicated under argon atmosphere using the X-TEMP2 [T. Kottke, D. Stalke, J. Appl. Crystallogr. 1993, 26, 615; D. Stalke, Chem. Soc. Rev. 1998, 27, 171.]. The structures were solved by direct methods (SHELXS) and refined on $F^{2}$ using the full-matrix least-squares methods of SHELXL [G. M. Sheldrick, Acta Crystallogr. Sect. A 2008, 64, 112]. Crystal structures deposited with the CCDC-Nr: 766244 (1), 766245 (2), 766246 (3), and 766247 (4). Space group, cell parameters and $R$-values with $[I>2 \sigma(I)]: \mathbf{1}: P \overline{1}, a=12.477(2)$, $b=17.529(3), c=19.792(3) \AA, \alpha=64.145(2), \beta=78.987(2)^{\circ}$, $\gamma=89.269(2)^{\circ}, w R 2=0.0953, R 1=0.0355 ; 2: P 2_{1} / n, a=10.578(2)$, $b=9.1589(19), c=15.943(3) \mathrm{A}, \beta=90.795(3)^{\circ}, w R 2=0.1113$, $R 1=0.0423$; 3: $P \overline{1}, a=9.3818(18), b=14.470(3), c=28.554(5) \AA$, $\alpha=88.542(3), \beta=85.980(2), \gamma=89.426(3)^{\circ}, w R 2=0.1843$, $R 1=0.0731 ; 4: C_{2} / c, a=19.891(3), b=8.2807(13), c=$ $32.847(5) \AA, \quad \beta=101.332(2)^{\circ}, w R 2=0.1287, \quad R 1=0.0537$. More details about the crystallographic data and the refinement can be found in the ESI. $\dagger$ These data can also be obtained free of charge from the Cambridge Crystallographic Data Centre via www.ccdc.cam.ac.uk/data-request/cif.

1 W. Schlenk and J. Holtz, Ber. Dtsch. Chem. Ges., 1917, 50, 262.

2 Organometallics in Synthesis - A Manual, ed. M. Schlosser, Wiley, Chichester, 2004.

3 F. Leroux, M. Schlosser, E. Zohar and I. Marek, The preparation of organolithium reagents and intermediates, in The Chemistry of Organolithium Compounds, ed. Z. Rappoport and I. Marek, John Wiley \& Sons, Chichester (GB), 2004, p. 435.

4 (a) F. Totter and P. Rittmeyer, Organolithium CompoundsIndustrial Applications and Handling, in Organometallics and Synthesis-A Manual, ed. M. Schlosser, Wiley, New York, 1994, p. 167; (b) T. L. Rathman and W. F. Bailey, Org. Process Res. Dev., 2009, 13, 144

5 (a) F. M. Piller, A. Metzger, M. A. Schade, B. A. Haag, A. Gavryushin and P. Knochel, Chem.-Eur. J., 2009, 15, 7192; (b) S. H. Wunderlich, M. Kienle and P. Knochel, Angew. Chem., 2009, 121, 7392 (Angew. Chem., Int. Ed., 2009, 48, 7256); (c) P. Knochel, W. Dohle, N. Gommermann, F. F. Kneisel, F. Kopp, T. Korn, I. Sapountzis and V. A. Vu, Angew. Chem., 2003, 115, 4438 (Angew. Chem., Int. Ed., 2003, 42, 7256).

6 R. E. Mulvey, Acc. Chem. Res., 2009, 42, 743.

7 L. Gupta, A. C. Hoepker, K. J. Singh and D. B. Collum, J. Org. Chem., 2009, 74, 2231.

8 (a) V. Gessner, C. Däschlein and C. Strohmann, Chem.-Eur. J., 2009, 15, 3320; (b) R. E. Dinnebier, U. Behrens and F. Olbrich, J. Am. Chem. Soc., 1998, 120, 1430; (c) A. Hope and P. P. Power, J. Am. Chem. Soc., 1983, 105, 5320; (d) D. Thoennes and E. Weiss, Chem. Ber., 1978, 111, 3157; (e) U. Schümann, J. Kopf and E. Weiss, Angew. Chem., 1985, 97, 222 (Angew. Chem., Int. Ed. Engl., 1985, 24, 215).

9 (a) D. Y. Curtin and E. W. Flynn, J. Am. Chem. Soc., 1959, 81, 4714; (b) W. Glaze and R. West, J. Am. Chem. Soc., 1960, 82, 4437; (c) R. Huisgen and W. Mack, Chem. Ber., 1960, 93, 332.

10 H. J. S. Winkler and H. Winkler, J. Am. Chem. Soc., 1966, 88, 969.

11 H. Schmidbaur, A. Schier and U. Schubert, Chem. Ber., 1983, 116, 1938.

12 P. García-Álvarez, D. V. Graham, E. Hevia, A. R. Kennedy, J. Klett, R. E. Mulvey, C. T. O'Hara and S. Weatherstone, Angew. Chem., 2008, 120, 8199 (Angew. Chem., Int. Ed., 2008, 47, 8079).

13 D. Hoffmann, A. Dorigo, P. v. R. Schleyer, H. Reif, D. Stalke, G. M. Sheldrick, E. Weiss and M. Geissler, Inorg. Chem., 1995, 34, 262.

14 (a) G. Schwab, D. Stern and D. Stalke, J. Org. Chem., 2008, 73, 5242; (b) G. Schwab, D. Stern, D. Leusser and D. Stalke, $Z$. Naturforsch., Sect. B., 2008, 62, 711; (c) Z. Fei, N. Kocher, C. J. Mohrschladt, H. Ihmels and D. Stalke, Angew. Chem., 2003, 115, 807 (Angew. Chem., Int. Ed., 2003, 42, 783).

15 D. Stern, N. Finkelmeier, K. Meindl, J. Henn and D. Stalke, Angew. Chem., 2010, 122, 7021 (Angew. Chem., Int. Ed., 2010, 49, 6869); reactivity and bond length is correlated by theoretical methods in this paper.

16 R. A. Gosaage, J. T. B. H. Jastrzebski and G. van Koten, Angew. Chem., 2005, 117, 1472 (Angew. Chem., Int. Ed., 2005, 44, 1448).

17 E. Lindner, H. Rauleder and W. Hiller, Z. Naturforsch., 1983, 38b, 417.

18 A. Kermagoret, F. Tomicki and P. Braunstein, Dalton Trans., 2008, 22, 2901.

19 I. Objartel, N. Pott and D. Stalke, Organometallics, 2010, 29, 5670. 